\title{
主観的認識推論システムの公理化
}

\section{森川 治*}

\begin{abstract}
D.Schwartzは，“明白に信じる”, “強く信じる”,“かなり合理的に信じる”，“なんとなく信じる”, “信じ るも信じなくもない”，“なんとなく信じない”，“かなり合理的に信じない”，“強く信じない”，“明白に信 じない”を取り扱う主観的認識推論システムを提案した。しかし，公理化は未解決問題としている。本論文 では，多値論理を使ってD.Schwartzの主観的認識推論システムの公理系を与え,健全性定理および完全性定 理を証明する。また，D.Schwartzとは異なる意味論(クリプケ(Kripke)モデル)を定義し，公理系を与え， 健全性定理打よび完全性定理を証明する。
\end{abstract}

キーワード：信念論理, ファジイ論理, 多値論理

\section{1 . はじめに}

D.Schwartzは，明白に信じる (unequivocally believe), 強く信じる (strongly believe)，かなり合理的に信 じる (fairly confidently believe)，なんとなく信じる (somewhat believe)，信じるも信じなくもない(neither believe nor disbelieve)，なんとなく信じない (somewhat disbelieve)，かなり合理的に信じない(fairly confidently disbelieve)，強く信じない(strongly disbelieve)，明白 に信じない (unequivocally disbelieve) を取り扱う主観 的認識推論システムを提案した，文献(3)，(4)，(5)参 照.

彼のシステムは言語グレード付き(明白に, 強く, かなり合理的に，なんとなく等)信念論理である.しか し, “明白に信じている”から“強く信じる”を導出でき るといった言語グレード間の強弱は考慮されていな い.この点は再考の必要がある.

彼のシステムでは“もし彼女が，ジョンは今年の夏 はヨーロッパで過ごすということをかなり合理的に信 じ，トムは来年の春までには学位がとれないと彼女が 強く信じていれば, ジョンとトムに関する少なくとも 一つは正しいと彼女は合理的に信じている.”このよう な推論が表現できる.また, 彼は言語レベルを二階に 分け，第一階レベルはファジイ論理で表現し，第二階 レベルは古典命題論理で表現している.彼は意味論を 与えているが, 公理化は未解決問題としている.

本論文の目的は，多值論理を使ってD.Schwartzの 主観的認識推論システムの公理系を与え, 健全性定理

\footnotetext{
$\dagger$ Axiomatization for the formal system of subjective epistemic reasoning

Osamu MORIKAWA

* 福島工業高等専門学校

Fukushima National College of Technology
}

および完全性定理を証明することである。

また，D.Schwartzの意味論をクリプケ(Kripke)モ デルを用いて定義し, 時点におおいて論理式Aを信じ る度合いを $\varphi(\square \mathrm{A}, s)(0 \leq \varphi(\square A, s) \leq 1)$ で表すとき，

(1) sでAを明白に信じる $\Leftrightarrow \varphi(\square A, s)=1$ ，

（2）sでAを強く信じる $\quad \Leftrightarrow \frac{6}{7} \leq \varphi(\square A, s)<1$,

（3）sでAをかなり合理的に信じる

（4）sでAをなんとなく信じる

$$
\Leftrightarrow \frac{5}{7} \leq \varphi(\square A, s)<\frac{6}{7}
$$

（5）sでAを信じるも信じなくもない

$$
\Leftrightarrow \frac{4}{7} \leq \varphi(\square A, s)<\frac{5}{7},
$$

（6）sでAをなんとなく信じない

$$
\Leftrightarrow \frac{3}{7}<\varphi(\square A, s)<\frac{4}{7},
$$

（7）sでAをかなり合理的に信じない

$$
\Leftrightarrow \frac{2}{7}<\varphi(\square A, s) \leq \frac{3}{7},
$$

（8）sでAを強く信じない $\Leftrightarrow 0<\varphi(\square A, s) \leq \frac{1}{7}$,

（9）sでAを明白に信じない $\Leftrightarrow \quad \varphi(\square A, s)=0$ ， と定義する.

この新しい意味論に対しても公理系を与え, 健全性 定理打よび完全性定理を証明する.

2 章から 4 章でD.Schwartzの意味論に対する公理 系を与え, 健全性定理打よび完全性定理の証明を与え る。 5 章では, クリプケ (Kripke) モデルによる意味論 を定義し，それに対する公理系を与え，健全性定理打 よび完全性定理を証明する。

\section{2. 行列}

2.1 真理值として $0 ， 1 ， 2 ， \ldots, 8$ をる. 直観的に は, 8 は真, 0 は偽を意味する. 以後真理值の集合を $\mathrm{T}$ で表わす。すなわち $\mathrm{T}=\{0,1,2, \ldots, 8\}$. 


\section{2 記号}

(1) 命題変数 : $p, q, r, \cdots$

(2) 論理記号 $: \neg, \vee, \wedge, \rightarrow, \neg, \vee \vee \wedge$.

(3) 様相記号 : $B_{m}(*)(m=0,1, \ldots, 8)$.

(4) 補助記号：括弧（，）。

\section{3 論理式}

次の様に帰納的に第一階論理式および第二階論理式 を定義する。

(1) 命題変数は第一階論理式である.

(2) $P$ および $Q$ が第一階論理式のとき, $\neg P, P \vee Q$, $P \wedge Q$ および $P \rightarrow Q$ も第一階論理式である.

(3) $P$ が第一階論理式のとき, $B_{m}(P)$ は第二階論理式 である。

(4) $A$ および $B$ が第二階論理式のとき, $\neg A, A \vee B$ お

よび $A \wedge B$ は第二階論理式である.

（5）以上だけが第一階論理式および第二階論理式であ る。

以後, 第一階論理式 $(P . Q, \ldots$ で表す)および第二階 論理式 $(A, B, \ldots$ で表す)を広義論理式 $(U, V, \ldots$ で表す $)$ と総称する.

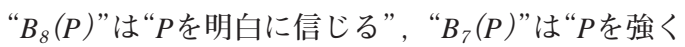

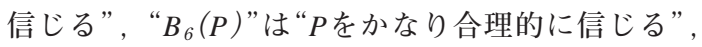

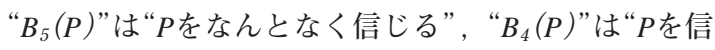

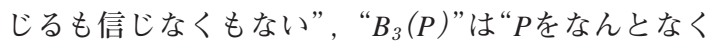

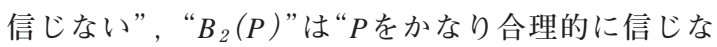

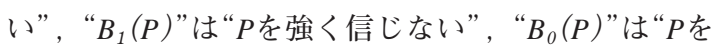
明白に信じない”と解釈する。

Gentzen型論理システム $L K$ を多値論理に拡張す る. GentzenのSequent $A_{1}, \ldots, A_{m} \rightarrow B_{1}, \ldots, B_{n}$ の意味 は, $A_{1}, \ldots, A_{m}$ のうち少なくとも一つは偽であるか, ま たは， $B_{1}, \ldots, B_{n}$ のうち少なくとも一つは真であるとい うことである. Sequentを多值論理に拡張して, 行列 $\left\{\left(U_{1}, m_{1}\right), \ldots,\left(U_{n}, m_{n}\right)\right\}$ を定義する. 行列の意味を, 広義論理式 $U_{1}$ が真理值 $m_{1}$ をとるか, $\cdots$, または, 広 義論理式 $U_{n}$ が真理值 $m_{n}$ をとることとする.

以下, 文献(1)，(2)に従い, 多值論理を説明する.

\section{4 行列}

次の条件を満足する広義論理式と真理值の対の有限 集合 $\left\{\left(U_{1}, m_{1}\right), \ldots,\left(U_{n}, m_{n}\right)\right\}$ を行列と定義する.

条件: $U_{1}, \ldots, U_{n}$,は第一階, または, 第二階論理 式. $m_{1}, \ldots, m_{n}$ は真理. $U_{k}(1 \leq k \leq n)$ が第二階論理式 のときは, $m_{k}=0$, または, $m_{k}=8$. また,$U_{k}$ をこの
行列の $m_{k}-$ 部分という.

\section{5 例}

$\left\{\left(\neg B_{1}(p), 0\right),(p \wedge q, 1),\left(B_{0}(q) \vee B_{2}(r), 8\right)\right\}$ は行列 である。しかし， $\left\{(p .0),\left(B_{2}(q), 1\right)\right\}$ は行列ではな い.

2.6 以後 $K, L, .$. で行列, $\Gamma, \Delta$ で広義論理式の集合を表 わす。

$S \subseteq T$ のとき , 行列 $\{(U, m) ; U \in \Gamma, m \in S\}$ を $(\Gamma, S)$ で, $(\{U\}, S) を(U, S)$ で, $(\Gamma,\{m\})$ を $(\Gamma, m)$ で, $(\{U\}, m) \cup(\Gamma, m)$ を $(\{U, \Gamma\}, m)$ で, $K \cup(\{U, m)\}$ を $K \cup(U, m)$ で表わす.

行列 $L$ の $m_{k}$-部分 $\left(m_{k}=0, \ldots, 8\right)$ のすべての広義の論 理式が行列 $M$ の $m_{k}$-部分に含まれているとき, $L \subseteq M$ で表わす。

$2.7 t_{0}=[0,0], \quad t_{1}=\left(0, \frac{1}{7}\right], \quad t_{2}=\left(\frac{1}{7}, \frac{2}{7}\right], \quad t_{3}=\left(\frac{2}{7}, \frac{3}{7}\right)$, $t_{4}=\left(\frac{3}{7}, \frac{4}{7}\right), t_{5}=\left[\frac{4}{7}, \frac{5}{7}\right), t_{6}=\left[\frac{5}{7}, \frac{6}{7}\right), t_{7}=\left[\frac{6}{7}, 1\right), t_{8}=[1,1]$ とおく.

$\mu:\{$ 第一階論理式 $\} \rightarrow[0,1]$ を以下のように定義す る.

(1) $0 \leq \mu(p) \leq 1$ ただし, pは命題変数,

(2) $\mu(\neg P)=1-\mu(P)$,

(3) $\mu(P \vee Q)=\operatorname{Max}\{\mu(P), \mu(Q)\}$,

(4) $\mu(P \wedge Q)=\operatorname{Min}\{\mu(P), \mu(Q)\}$,

(5) $\mu(P \rightarrow Q)=\operatorname{Max}\{1-\mu(P), \mu(Q)\}$

$v:\{$ 第二階論理式 $\} \rightarrow\{0,8\}$ を次のように定義する.

(6) $v\left(B_{m}(P)\right)=8 \Leftrightarrow \mu(P) \in t_{m}(\mathrm{~m}=0,1, \ldots, 8)$.

(7) $v(\neg A)=8 \Leftrightarrow v(A)=0$.

(8) $v(A \vee B)=8 \Leftrightarrow v(A)=8$ ，または，v(B)=8.

(9) $v(A \wedge B)=8 \Leftrightarrow v(A)=v(B)=8$.

参考文献(5)に打いてD.Schwartzはルカシェヴィツ の含意 : $\mu(P \stackrel{L}{\longrightarrow} Q)=\operatorname{Min}\{1-\mu(P)+\mu(Q), 1\}$ の導入 を検討しているが，任意の $\mathrm{i}, \mathrm{j}$ に対して $\mu(P) \in t_{i}$ かつ $\mu(Q) \in t_{j}$ のとき $\mu(P \rightarrow Q) \in t_{k}$ を満足する k が唯一つ存 在するという性質が成り立たない。従って本稿では ルカシェヴィツの含意を導入せず, クリーネの含意： $\mu(P \rightarrow Q)=\operatorname{Max}\{1-\mu(P), \mu(Q)\}$ を導入し, 健全性お よび完全性定理を証明する. 本論理システムにルカシェ ヴィツの含意を導入することは未解決問題である。 
第二階論理に, $A \stackrel{\bullet}{\longrightarrow} B=\neg A \stackrel{\bullet}{ }=\stackrel{\bullet}{ }$ として古典論理の 含意は導入できる。

任意の $\mu$ に対して,$(P, m)=L$ かつ $\mu(P) \in t_{m}$ を満 足する第一階論理式 $P$ が存在する, または, $(A, v(A)$ $\in L$ を満足する第二階論理式 $A$ が存在するとき, 行列 $L$ は恒真であると定義する。

行列 $\left\{\left(U_{1}, \mathrm{~m}_{1}\right), \ldots,\left(U_{k}, \mathrm{~m}_{\mathrm{k}}\right)\right\}$ が恒真であるとは, 定 義より広義論理式 $U_{1}$ が真理値 $\mathrm{m}_{1}$ をとるか, $\ldots$, ま たは, 論理式 $U_{n}$ が真理值 $\mathrm{m}_{\mathrm{n}}$ をとることである。

\section{3. 公理系}

Gentzen型論理システム $L K$ を多值論理に拡張した 公理系を導入する。この公理系は公理と推論規則から なる, 文献(1)，(2)参照.

\section{1 公理}

$(P, 0) \cup(P, 1) \cup \ldots \cup(P, 8)$

\section{2 推論規則}

（1）増 $L \subseteq K$ のき，

$$
\frac{L}{K}
$$

(2) 三段論法 $k \neq m$ のとき

$$
\frac{L \cup(A, m), K \cup(A, k)}{L \cup K}
$$

(3) 一階論理記号

$$
\begin{aligned}
& (\neg) \frac{L \cup(P, m)}{L \cup(\neg P, 8-m)} \\
& (\vee) \frac{L \cup(P, m), L \cup(Q, n)}{L \cup(P \vee Q, \max (m, n))} \\
& (\wedge) \frac{L \cup(P, m), L \cup(Q, n)}{L \cup(P \wedge Q, \min (m, n))} \\
& (\rightarrow) \frac{L \cup(P, m), L \cup(Q, n)}{L \cup(P \rightarrow Q, \max (1-m, n))}
\end{aligned}
$$

(4) 論理記号 $B_{m}$

$$
\frac{L \cup(P, m)}{L \cup\left(B_{m}(P), 8\right)} \quad \frac{L \cup(P, n)}{L \cup\left(B_{m}(P), 0\right)}(m \neq n)
$$

（5）第二階論理記号

$$
\stackrel{\bullet}{(\neg)} \frac{L \cup(A, m)}{L \cup(\neg A, 8-m)} \quad(m=0,8)
$$

$$
\begin{aligned}
& \text { ( }) \frac{L \cup(\{A, B\}, 8)}{\dot{\bullet}} \quad \frac{L \cup(A, m), L \cup(B, n)}{\dot{\bullet}(A \vee B, 8)} \quad \frac{L \cup(A \vee B, \max (m, n))}{L} \\
& (\mathrm{~m}, \mathrm{n}=0,8) \\
& \text { - }(\wedge) \frac{L \cup(\{A, B\}, 0)}{L \cup(A \wedge B, 0)} \quad \frac{L \cup(A, m), L \cup(B, n)}{L \cup(A \wedge B, \min (m, n))} \\
& (m, n=0,8)
\end{aligned}
$$

3.3 行列 $L$ が証明可能であることを次のように定義す る.

（1）公理は証明可能である.

(2) 推論規則の前提 (線の上の行列)がすべて証明可能 であるならば，その結論(線の下の行列)も証明可 能である。

\section{4 補題}

次の行列は証明可能である.

(1) $(A, 0) \cup(A, 8)$.

(2) $\left(B_{m}(P) \wedge B_{n}(Q), 0\right) \cup\left(B_{\min (m, n)}(P \wedge Q), 8\right)$.

(3) $\left(B_{m}(P) \wedge B_{n}(Q), 0\right) \cup\left(B_{\max (m, n)}(P \vee Q), 8\right)$.

(4) $\left(B_{m}(\neg P), 0\right) \cup\left(B_{8-m}(P), 8\right)$.

(5) $\left(B_{8-m}(P), 0\right) \cup\left(B_{m}(\neg P), 8\right)$.

(6) $\left.\stackrel{\bullet}{\bullet} B_{m}(P), 0\right) \cup\left(\underset{n \neq m}{\stackrel{\bullet}{\vee}} B_{n}(P), 8\right)$.

(7) $\left.\underset{n \neq m}{\stackrel{\bullet}{\vee}} B_{n}(P), 0\right) \cup\left(\neg B_{m}(P), 8\right)$.

証明 (2)のみ証明する。他の場合も同様.

$$
\frac{\frac{(P, 0) \cup \ldots \cup(P, m) \cup \ldots \cup(P, 8)}{\left(B_{m}(P), 0\right) \cup(P, m)} \frac{(Q, 0) \cup \ldots \cup(Q, n) \cup \ldots \cup(Q, 8)}{\left(B_{n}(Q), 0\right) \cup(Q, n)}}{\left(\left\{B_{m}(P), B_{n}(Q)\right\}, 0\right) \cup(P \wedge Q, \min (m, n))}
$$

\section{5 健全性定理}

行列 $L$ が証明可能ならば, $L$ は恒真である. 証明 証明可能性の定義に関する数学的帰納法で証明 できる。

\section{4. 完全性定理}

以後, 行列 $L$ の-部分に現われる広義論理式の集 合を $L_{m}$ で, $\bigcap_{k \neq m} L_{k}$ を $L_{m}^{*}$ で, $(A, T-\{m\})$ を $(A, \underline{m})$ 
で略記する。

推論規則 (三段論法)を使って，次の補題を得る.

\section{1 補題}

$L$ が証明不可能のとき

（1）任意の第一階論理式 $P$ に対して,$L \cup(P, \underline{m})$ が証 明不可能となる $m$ が存在する。

(2) 任意の第二階論理式 $A$ に対して, $L \cup(A, \underline{m})$ が証 明不可能となる $m(m=0,8)$ が存在する.

以後 証明不可能な行列 $K$ を一つ固定する.

\section{2 定義}

広義論理式 $U$ の部分論理式を次のように定義する.

(1) $U$ 自身は $U$ の部分論理式である.

(2) $U$ が $P \vee Q, P \wedge Q, P \rightarrow Q, A \vee B, A \wedge B$ のいずれ かのとき, $P, Q, A, B$ の部分論理式は $U$ の部分論 理式である。

(3) $U$ が $P, B_{m}(P), \neg A$ のいずれかのとき, $P, A$ の 部分論理式は $U$ の部分論理式である.

\section{3 定義}

$F L(K)$ で $K$ に現われる広義論理式の部分論理式すべ ての集合を表わす．行列 $L$ が証明不可能で，任意の第 一階論理式 $P \in F L(K)$ に対して, $P \in L_{m}^{*}$ を満足する $m$ が存在し，かつ，任意の第二階論理式 $A \in F L(K)$ に対 して,$A \in L_{m}^{*}(m=0,8)$ を満足する $m$ が存在すると き， $L$ をcompleteと定義する. completeな行列すべ ての集合を $C(K)$ で表わす。

4.4４.6の証明は省略する。詳細は文献 (1)，（2)参 照.

\section{4 補題}

$P, A \in F L(K), L \in C(K)$ に対して

(1) $P \in L_{m}^{*} \Leftrightarrow L \cup(P, m)$ は証明可能.

(2) $P \in L_{m}^{*}$ を満足する $m$ が唯一つ存在する.

(3) $A \in L_{m}^{*} \Leftrightarrow L \cup(A, m)$ が証明可能, $(m=0,8)$.

(4) $A \in L_{m}^{*}$ を満足する $m(m=0,8)$ が唯一つ存在す る.

\section{5 (リンデンバウムの補題)}

行列 $L$ が証明不可能なとき， $L \subseteq M$ を満足するcompleteな行列 $M \subseteq C(L)$ が存在する.
4.6 $L \in C(K), \neg P, P \vee Q, P \wedge Q, P \rightarrow Q, B_{n}(P)$,

$\neg A, A \vee B, A \wedge B \in F L(K)$ のき,

(1) $P \in L_{m}^{*} \Rightarrow \neg P \in L_{8-m}^{*}$

(2) $P \in L_{m}^{*}, Q \in L_{n}^{*} \Rightarrow P \vee Q \in L_{\max (m, n)}^{*}$.

(3) $P \in L_{m}^{*}, Q \in L_{n}^{*} \Rightarrow P \wedge Q \in L_{\min (m, n)}^{*}$.

(4) $P \in L_{m}^{*}, Q \in L_{n}^{*} \Rightarrow P \rightarrow Q \in L_{\max (1-m, n)}^{*}$.

(5) $B_{m}(P) \in L_{8}^{*} \Leftrightarrow P \in L_{m}^{*}$.

(6) $\stackrel{\bullet}{\neg} A \in L_{8}^{*} \Leftrightarrow A \in L_{0}^{*}$.

(7) $\dot{A \vee B} B \in L_{8}^{*} \Leftrightarrow A \in L_{8}^{*}$ または $B \in L_{8}^{*}$.

(8) $A \wedge B \in L_{8}^{*} \Leftrightarrow A \in L_{8}^{*}$ かつ $B \in L_{8}^{*}$.

\section{7 定義}

canonical model $\left(\bar{\mu}_{K}, \bar{v}_{K}\right)$ を次のように定義する.

(1) $\bar{\mu}_{K}$ : 第一階論理式 $\left.P ; P \in F L(K)\right\} \rightarrow[0,1]$

$$
\bar{\mu}_{K}(P)=\frac{m}{8} \Leftrightarrow P \in K_{m}^{*}
$$

(2) $\bar{v}_{K}:\{$ 第二階論理式 $A ; A \in F L(K)\} \rightarrow\{0,8\}$

$$
\bar{v}_{K}(A)= \begin{cases}8 & \left(A \in K_{8}^{*}\right) \\ 0 & \left(A \in K_{0}^{*}\right)\end{cases}
$$

\section{8 補題}

$\bar{\mu}_{K}, \bar{v}_{K}$ は2.7 (1) 〜 (9) を満足する.

証明 (2), (5)のみ証明する。他の場合も同様に証明 できる。

(2) $\bar{\mu}_{K}(P)=\frac{m}{8}$ のとき, $P \in L_{m}^{*}$. 補題4.6(1) より, $\neg P \in K_{8^{-} m}^{*}$. 従って, $\bar{\mu}_{K}(\neg P)=\frac{8-m}{8}=1-\frac{m}{8}$.

$\therefore \bar{\mu}_{K}(P)+\bar{\mu}_{K}(\neg P)=1$.

(5) $\bar{v} K\left(B_{m}(P)\right)=8 \Leftrightarrow\left(B_{m}(P)\right) \in K_{8}^{*}$

$$
\begin{aligned}
& \Leftrightarrow P \in K_{m}^{*} \\
& \Leftrightarrow \bar{\mu}_{K}(P)=\frac{m}{8} \in t_{m} .
\end{aligned}
$$

\section{9 定理（完全性定理）}

行列 $L$ が恒真のとき, $L$ は証明可能である.

証明 対偶を証明する。すなわち， $L$ が証明不可能で 
あると仮定する。 4.5 (リンデンバウムの補題)より， $L$ $\subseteq M$ を満足する completeな行列が $M \in C(L)$ 存在す る. $K=M$ とおいて canonical modelをつくれば, 任意 の第一階論理式 $P \in L_{m}$ に対して $P \in M_{m}$. 従って $P \in$ $M_{n}^{*}$ を満足する $n(n \neq m)$ が存在する. $\bar{\mu}_{K}(P)=\frac{n}{8} \in t_{n}$. 従って $\bar{\mu}_{K}(P) \notin t_{m}$. 第二階論理式の場合も同様に証 明できる。従って $L$ は恒真ではない。

\section{5. クリプケ (Kripke) モデル}

信念を取り扱う論理体系は様相論理 $K D 45$ である ことより, 信じる度合いを取り扱う新しい論理体系を 考察する, 文献 (6) 参照.

$1(1) \sim(9)$ に従って, “状態 $\mathbf{s}$ で $B_{m}(P)$ が成り立つ” $\Leftrightarrow$ “sで行列 $(\square P, m)$ が成り立つ” $\Leftrightarrow$ “ $\varphi(\square P, s) \in t_{m}$ ”が 成り立つよう論理体系を導入する。

\section{1 論理式}

次の様に帰納的に論理式を定義する。

(1) 命題変数は論理式である.

(2) $A$ およびBが論理式のとき, $\neg A, A \vee B, A \wedge B, A$ $\rightarrow B$ および $\square A$ は論理式である.

\section{2 行列}

論理式と真理值の対の有限集合 $\left\{\left(A_{1}, m_{1}\right), \ldots\right.$, $\left.\left(A_{n}, m_{n}\right)\right\}$ を行列と定義する.

\section{3 定義}

$(W, R, \varphi)$ がクリプケ (Kripke) モデルであるとは,

(1) $W$ は空でない集合.

(2) $R$ は次の条件を満足する $W$ 上の関係.

$(2-1)$ 継続的：任意の $s$ に対して $s R t$ を満たす $t$ が存在する。

$(2-2)$ 推移的: $s R t$ かつ $t R u$ ならば $s R u$.

(2-3) 対称的 : sRt ならば $t R s$.

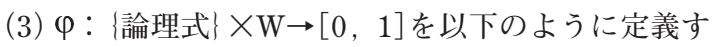
る.

(1) $0 \leq \varphi(p, s) \leq 1$. ただし, pは命題変数.

(2) $\varphi(\neg A, s)=1-\varphi(A, s)$.

(3) $\varphi(A \vee B, s)=\operatorname{Max}\{\varphi(A, s), \varphi(B, s)\}$.

(4) $\varphi(A \wedge B, s)=\operatorname{Min}\{\varphi(A, s), \varphi(B, s)\}$.

(5) $\varphi(A \rightarrow B, s)=\operatorname{Max}\{1-\varphi(A, s), \varphi(B, s)\}$

(6) $\left.\varphi(\square A, s)=\frac{1}{8} \operatorname{Min}\left\{n ;\{\varphi(A, t) ; s R t\} \cap t_{n} \neq \phi\right\}\right\}$.

定義より次の命題を得る.

\section{4 命題}

(1)～(3) が成り立つ.
(1) $\varphi(\square A, s)=0 \Leftrightarrow \varphi(A, u) t_{0}$ かつ $s R u$ を満足する $u$ が存在する.

(2) $\varphi(\square A, s)=1 \Leftrightarrow s R u$ を満足する任意の $u$ に対し $\tau, \varphi(A, u) \in t_{8}$.

(3) $\varphi(\square A, s)=\frac{m}{8}$

$\Leftrightarrow s R u$ を満たす任意の $u$ に対して $\varphi(A, u) \in t_{m} \cup t_{m+1} \cup \ldots \cup t_{8}$ かつ $\varphi(A, v) \in t_{m}$ および $s R v$ を満たす $v$ が存在する $(m \neq 0,8)$.

(4) $\varphi(\square A, s) \in t_{m}$ かつ $s R t$ のとき, $\varphi(\square A, t) \in t_{m}$.

任意のクリプケ (Kripke) モデル $(W, R, \varphi)$ と任意の 要素 $s \in W$ に対して, $(A, m) \in L$ かつ $\varphi(A, s) \in t_{m}$ を 満足する論理式 $A$ 打よび $m$ が存在するとき, 行列 $L$ は恒真であると定義する。

\section{5 公理系}

次の公理および推論規則からなる.

\subsection{1 公理}

(1) $(A, 0) \cup(A, 1) \cup \ldots \cup(A, 8)$

(2) $(\neg A,\{0, \ldots, m\}) \cup .(\square \neg \square A,\{m+1, \ldots, 8\})$

\subsection{2 推論規則}

（1）増 $L \subseteq K$ のとき, $\frac{L}{K}$

（2）三段論法 $\mathrm{k} \neq \mathrm{m}$ のとき, $\frac{L \cup(A, m), K \cup(A, k)}{L \cup K}$

(3) (ᄀ) $\frac{L \cup(A, m)}{L \cup(\neg A, 8-m)}$

(4) ( V) $\frac{L \cup(\{A, B\}, 8)}{L \cup(A \vee B, 8)} \frac{L \cup(A, m), L \cup(B, n)}{L \cup(A \vee B, \max (m, n))}$

(5) $(\wedge) \frac{L \cup(\{A, B\}, 0)}{L \cup(A \wedge B, 0)} \quad \frac{L \cup(A, m), L \cup(B, n)}{L \cup(A \wedge B, \min (m, n))}$

(6) $(\rightarrow) \frac{L \cup(A, m), L \cup(B, n)}{L \cup(A \rightarrow B, \max (1-m, n))}$

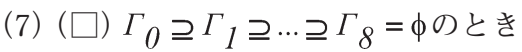

$$
\text { (7.1) } \frac{\bigcup_{k=0}^{8}\left(\Gamma_{k}, k\right)}{\bigcup_{k=0}^{8}\left(\square \Gamma_{k}, k\right)}
$$


(7.2) $\frac{\bigcup_{k \neq m}^{\cup}\left(A, \square \Gamma_{k}, k\right) \cup\left(\square \Gamma_{m}, m\right)}{\bigcup_{k \neq m}\left(\square A, \square \Gamma_{k}, k\right) \cup\left(\square \Gamma_{m}, m\right)}$

(8) $\frac{\underset{k \leq m}{\cup}\left(\square \Gamma_{k}, k\right) \cup \underset{k \geq m+1}{\cup}\left(A, \square \Gamma_{k}, k\right)}{\underset{k \leq m}{\cup}\left(\square \Gamma_{k}, k\right) \cup \underset{k \geq m+1}{\cup}\left(\square A, \square \Gamma_{k}, k\right)}$

\section{6 補題}

次の行列は証明可能である。

(1) $(A,\{0, \ldots, m\})) \cup(\neg A,\{0, \ldots, 7-m\})$

(2) $(\square A,\{0, \ldots, m\})) \cup(\square \square A,\{m+1, \ldots, 8\})$

$3 ， 4$ 章と同様にして次の定理を得る，文献 (1), (2) 参照.

\section{7 健全性の定理}

行列 $L$ が証明可能ならば， $L$ は恒真である. 証明 証明の構成に関する数学的帰納法で証明する.

\section{8 補題}

$L$ が証明不可能のとき

任意の論理式 $A$ に対して, $\Gamma \cup(A, \underline{m})$ が証明不可能 となる $\mathrm{m}$ 多在する.

以後 証明不可能な行列 $K$ を一つ固定する.

\section{9 定義}

$F L(K)$ で $K$ に現われる論理式の部分論理式すべての 集合を表わす，行列 $L$ が証明不可能で，任意の論理式 $A \in F L(K)$ に対して,$A \in L_{m}^{*}$ を満足する $m$ が存在す るとき， $L$ をcompleteと定義する. completeな行列す べての集合を $C(K)$ で表わす.

5.10～5.12の証明は省略する。詳細は文献 (1), 参照.

5.10 任意の論理式 $A, L \in C(K)$ に対して

(1) $A \in L_{m}^{*} \Leftrightarrow L \cup(A, m)$ は証明可能.

(2) $A \in L_{m}^{*}$ を満足する $m$ が唯一つ存在する.

\subsection{1 (リンデンバウムの補題)}

行列 $L$ が証明不可能なとき, $L \subseteq M$ を満足するcompleteな行列 $M \in C(K)$ が存在する.

\section{$5.12 L \in C(K)$ に対して}

(1) $(A, 0) \cup \ldots \cup(A, m) \cup(B, m+1) \cup \ldots \cup(B, 8)$ が証 明可能かつ $A \in L_{0 \ldots m}$ のとき, $B \in L_{o} \ldots m$

(2) $A \in L_{m}^{*}$ のとき, $\neg A \in L_{8}^{*}-m$.
(3) $A \in L_{m}^{*}, B \in L_{n}^{*}$ のとき, $A \vee B \in L_{\max }^{*}(m, n)$.

(4) $A \in L_{m}^{*}, B \in L_{n}^{*}$ のとき, $A \wedge B \in L_{\min }^{*}(m, n)$.

(5) $A \in L_{m}^{*}, B \in L_{n}^{*}$ のとき, $A \rightarrow B \in L_{\max }^{*}(1-m, n)$.

\subsection{3 定義}

canonical model $(C(K), \bar{R}, \bar{\varphi})$ を次のように定義す る.

(1) $\bar{\varphi}_{K}:\{$ 論理式 $\} \rightarrow[0,1]$

$\bar{\varphi}(A, K)=\frac{m}{8} \Leftrightarrow A \in K_{m}^{*}$

(2) 任意の $L, M \in C(K)$ に対して,$L \bar{R} M$ を次のように 定義する。

$L \bar{R} M$ ，任意の論理式 $A$, 真理值 $\mathrm{m} \in \mathrm{T} に$ 対して

$$
\square A \in L_{0} \ldots m \text { ならば } A \in M_{0} \ldots m \text {. }
$$

5.11 補題 (Lindenbaumの補題) より, 次の補題を得 る.

\subsection{4 補題}

$$
C(K) \neq \phi
$$

\subsection{5 補題}

任意の $L, M, N \in C(K)$ に対して，（1）～(3) が成り 立つ。

(1) $L \bar{R} L^{\prime}$ かつ $L^{\prime} \in C(K)$ を満たす $L^{\prime}$ が存在する.

(2) $L \bar{R} M$ のとき, $M \bar{R} L$.

(3) $L \bar{R} M$ かつ $M \bar{R} N$ のとき, $L \bar{R} N$.

証明 (1) $L_{0, \ldots k}, L_{k}$, および $L$ は証明不可能より，

$\bigcup_{k=0}^{8}\left(\left\{\square C \in L_{0} \ldots k\right\}, k\right)$ は証明不可能. 5.5.2(7)よ り, $\bigcup_{k=0}^{8}\left(\left\{C ; \square C \in L_{0} \ldots k\right\}, k\right)$ は証明不可能. 5.11 Lindenbaumの補題より, $L \bar{R} M$ を満たす $M \in C(K)$ が存 在する。

(2) $L \bar{R} M$ かつ, 次の条件を満足する論理式 $A$ およ び真理值が $m$ が存在すると仮定して矛盾を導く.

$\square A \in M_{0 . . m}$ かつ $A \notin L_{0} \ldots m$. Lの条件より $A \in L_{0}^{*}$ $\cup \ldots \cup L_{m}^{*} .5 .10$ より, $L \cup(A, 0)$, または, $\ldots, L \cup(A$, $m)$ は証明可能. 5.5.2(3)より, $L \cup(\neg A, 8-m)$, また は, $\ldots, L \cup(\neg A, 8)$ は証明可能. $5.10 よ り \neg A \in L_{8-m}^{*} \cup$ $\ldots \cup L_{8}^{*}$. 従って $\neg A \in L_{0 \ldots 7-m}$.

公理 (2) および5.12(1)より, $\square \neg \square A \in L_{0 . .7-m}$.

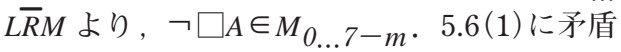

(3) 5.6(2)より証明できる.

5.13〜 5.15より次の補題を得る. 


\subsection{6 補題}

canonical model $(C(K), \bar{R}, \bar{\varphi})$ はクリプケ (Kripke) モデルである.

\subsection{7 補題}

任意の $L \in C(K)$, 任意の $A \in F L(K)$ 対して, $A \in L_{m}^{*}$ のとき, $\bar{\varphi}(A, L) \in t_{m}$.

証明 論理式Aの構成に関する帰納法で証明する.

(1) $A=p$ (p：命題変数)のとき, 定義より明らか.

(2) $A=\neg B, B \vee C, B \wedge C$ の証明は省略する.

(3) $A=\square B$ のとき,

(3-1) $L \bar{R} M$ を満たす任意の $M$ に対して ,

$\square B \in L_{m}^{*} \subset L_{0 \ldots m-1}$ より,

$B \in M_{0 \ldots m-1}=M_{m}^{*} \cup \ldots \cup M_{8}^{*}$, 帰納法の仮定より, $\bar{\varphi}(A, M) \in t_{m} \cup \ldots \cup t_{8}$.

(3-2) $\square B \in L_{m}^{*}, \quad L_{0 \ldots k} \subset L_{k}$, および $L$ は証明不 可能より, $\underset{k \neq m}{\cup}\left(\square B,,\left\{\square C \in L_{0 . . k}\right\}, k\right) \cup(\{\square C \in$ $\left.L_{0 \ldots m^{\prime}}, m\right)$ は証明不可能. 5.5.2(7.2)より, $\underset{k \neq m}{\cup}(B$, $\left.\left\{C ; \square C \in L_{0 \ldots k}\right\}, k\right) \cup\left(\left\{C ; \square C \in L_{0 \ldots m}\right\}, m\right)$ は証明 不可能. 5.11 Lindenbaumの補題より, $L \bar{R} M$ かつ $B \in$ $M_{m}^{*}$ を満たす $M \in C(K)$ が存在する.

帰納法の仮定より, $\bar{\varphi}(B, M) \in t_{m}$ を満たす $M$ が存 在する. 5.4 より, $\bar{\varphi}(\square B, L) \in t_{m}$. 以上をまとめて, 次の完全性定理を得る。

\subsection{8 定理（完全性の定理）}

行列 $L$ が恒真のとき， $L$ は証明可能である. 証明 対偶を証明する.すなわち, Lが証明不可能であ ると仮定して $L$ を偽とする canonical modelを作る. $L$ が証明不可能であると仮定する。 5.11 Lindenbaum の補題より， $L \subset M$ かつ $M \in C(L)$ を満たす $M$ が存在 する. $K=M$ とおいて canonical modelをつくれば, 5.13〜 5.17より，任意の $A \in L_{m}={ }_{k \neq m}^{\cap} L_{k}^{*}$ に対して $L \subset$ $M よ り, \bar{\varphi}_{K}(A, M)=k \neq m$. 従つて $L$ は恒真ではな i).

\section{6. まとめ}

本論文においてD.Schwartzの主観的認識推論への 公理系を与え, 健全性の定理および完全性定理の証明 を与えた。また, D.Schwartzの意味論をクリプケ (Kripke) モデルを用いて定義し, それに対する公理系 を与え, 健全性の定理および完全性定理を証明した。 今後は, 共有知識を取り扱えるように主観的認識推論 システムを拡張し，言語グレード付き共有知識とナッ シュ均衡の関係を考察する予定である。

\section{参 考 文 献}

[1] O.Morikawa, Some modal logics based on a threevalued logic, Notre Dame Journal of Logic, 30 (1989), $130-137$.

[2] O.Morikawa, An extended Gentzen-type formulation of a many-valued modal prepositional logic based on Zadeh's similarity relation, Fuzzy Sets and Systems 101 (1999), 115- 124.

[ 3 ] D.G. Schwartz, Axioms for a theory of semantic equivalence, Fuzzy Sets and Systems 21 (1987), 319-349.

[ 4 ] D.G. Schwartz, Layman's probability theory : A calculus for reasoning with linguistic likelihood, Information Sciences, 126 (2000), 71-82.

[ 5 ] D.G. Schwartz, Agent- oriented epistemic reasoning : Subjective conditions of knowledge and belief, Artificial Intelligence 148 （2003） 177- 195.

[6] 東条敏, 言語・知識・信念の論理 オーム社 2006

(2008年 9 月 10 日 受付)

(2009年 7 月13日 採録)

[問い合わせ先 ]

テ970-8034 いわき市平上荒川長尾30

福島工業高等専門学校

福島工業高等専門学校 コミュニケーション情報学科

森川治

TEL：0246-46-0853 (直通)

FAX : 0246-46-0859

E-mail : morikawa@fukushima-nct.ac.jp 


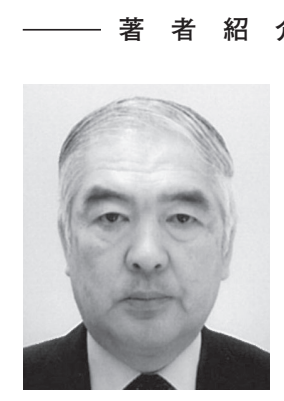

介

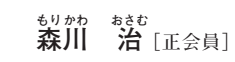

福島工業高等専門学校コミュニケー

ション情報学科

昭和 47 年 3 月 東京教育大学大学院

理学研究科応用数理学専攻修士課程終

了. 昭和 47 年 6 月福島工業高等専門

学校助手. 平成 9 年 4 月教授となり現

在に至る. 博士 (理学). 数理論理学

(特に多值様相論理学) の研究に従事.

日本経営工学会, 哲学論理学会各会

員.

\section{Axiomatization for the formal system of subjective epistemic reasoning}

by

\section{Osamu MORIKAWA}

\section{Abstract :}

D.G. Schwartz introduced the formal system $\Sigma$ of subjective epistemic reasoning in which belief was measured along a series of linguistic degrees, e.g. unequivocally believes, strongly believes, fairly confidently believes, somewhat believes, neither believes nor disbelieves, somewhat disbelieves, fairly confidently disbelieves, strongly disbelieves, unequivocally disbelieves. The purpose of this paper is to present two axiomatizations for D.G. Schwartz's system, by using the matrix of many-valued logic. Then we prove the completeness theorem as well as the soundness theorem.

Keywords : Belief logic, Fuzzy logic, Many-valued logic

\section{Contact Address : Osamu MORIKAWA}

Fukushima National College of Technology

Taira, Iwaki, Fukushimaken, 970-8034, JAPAN

TEL : 0246-46-8053

FAX : 0246-46-0859

E-mail : morikawa@fukushima-nct.ac.jp 